\title{
Imminent Attack in Necessary Defense, as Provided for in Albanian Criminal Law. Comparative Aspects
}

\section{Dorina Hoxha}

\author{
Criminal Department, Faculty of Law, UT
}

Email: dohory@yahoo.it

Doi:10.5901/ajis.2014.v3n6p241

\begin{abstract}
In Article 19, of the Albanian Criminal Code, necessary defense is provided as one of criminal responsibility exceptional cases. In fact, this provision specifies that a person bears no criminal responsibility if he commits the act while being compelled to protect his or somebody else's life, health, rights and interests from an unjust, real and imminent attack. This provision finds support in the ratio that is created between the option to protect a legal object which is before a potential and near affect and the latter on another object from which unlawfulness derives from. There are two human facts in front of each other related to the necessary defense, and they bear the same criminal responsibility. With this we must realize that we are dealing with facts which if they stay opposite to each other under a judicial - criminal assessment they are both presented as offense figures. In other words, unjust attack is the action which is not only hazardous for society but also illegal, provided as such by the criminal law and that the counterattack shall constitute an offense also provided by the criminal law. In this paper we will analyze the characteristics of one of the main conditions of the necessary defense, related to the imminent attack. Imminent attack is enriched in two forms. First attack has started and continues and secondly it is expected to certainly start. These notions are often not clear even for Albanian judicial practice. Imminent attack should be distinguished from future and completed attack. Albanian criminal law has provided the existence of imminent attack not only objectively, but also considering psychological or subjective criteria of the person, and this is supported by the Supreme Court practice. Standpoint between imminent attack, institute of attempt and waiver from the commission of an offense plays particular significance, and this paper will analyze their common characteristics.
\end{abstract}

Keywords: imminent attack; necessary defense; time; attempt; comparative profile;

\section{Characteristics of Imminent Attack in Necessary Defense}

One of necessary conditions for the necessary defense is that the unjust and real attack must be imminent at the same time. Institute of necessary defense is provided for in the European Convention of Human Rights, in article 2, point 4, providing that: "Deprivation of life shall not be regarded as inflicted in contravention of the Law when it results from the use of force in absolutely objective and necessary circumstances:

a. in defense of any person from unlawful violence;

b. in order to effect a lawful arrest or to prevent the escape of a person lawfully detained;

c. in action lawfully taken for the purpose of quelling a riot or insurrection

Defense of life, health and legitimate interests is also provided for by Law No.8290, dated 24.02.1998 "On the use of firearms", Article 2 and 3 . This kind of defense finds legal support in the legally - criminal institute of necessary defense, provided for in Article 19 of the Criminal Code.

In fact, this norm has set impunity of the person who has committed a criminal offense, having been forced by the necessity to repel an imminent attack from an unjust violation against life, health, law, his interest or any other person. By the provision of Article 19 of the Criminal Code we realize that "time" element in necessary defense plays a particular role, because based on it there is determined accidental affect to life, health or rights or interests of the person on whom there is addressed a present and actual attack.

Therefore, we realize that the "time" element during the attack (action) plays a crucial role in the exclusion of criminal responsibility, for the fact that the attack should be imminent and not later, so that we could be before necessary defense. Counterattack is a legitimate defense if exercised before a right has been affected and according to a substantial probability that it will come in the future. How does the theory of criminal law consider an imminent attack? How does the "time" element affect the determination of "imminent" to attack?

Under the theory of Albanian criminal law, imminent attack means exactly the time at which the attack has 
occurred.

The time when such attack occurs does not necessarily start and immediately ends without duration because the doctrine considers as imminent the attack that has started and which has not finished yet, must be life threatening or which is visibly expected and will certainly start imminently, risking directly the rights and interests protected by law (Elezi, Kaçupi, Haxhia, 2012, p. 137). Real attack is the one that is close or very close to the person who counterattacks (Peverati, 1942, p. 153).

Imminent means taking an action or doing it in a near future, the movement of people, expression of energies that contain a threat that is on the way to its realization. So, in this sense, the designation of the attack lies in the existence of a report almost immediate, between verification of reasons and the coming of consequence. Consequence cannot be understood as a purely theoretical or remote possibility, but a near opportunity to develop the causal link. So, the imminent attack exists in the considerable opportunity, not in the future, not in the past, to causing a harmful consequence. Given that the notion of imminent attack contains two definitions we are hereby analyzing the first aspect.

\subsection{Attack has started and continues related to the "time" element}

Imminent attack in necessary defense is not expressed only by static illegal or unchangeable unjust actions, but also in those cases in which the attack takes time, so that the attack by the attacker does not finish in a single act or threatening incident (Italian Court decision No. 05429, dated 9.5.1992).

In this first standpoint, analysis refers to actions that take time consistently, where attack does not finish in the immediate threat of a rapid and inevitable infringement, but time is estimated based on all of the time duration of hazardous and illegal situation. Therefore, it is required that during the action or counterattack there must be openly displayed the will of the attacker to damage or infringe and this is assessed on the basis of prolonged and uninterrupted behavior.

The notion of attack that has started and continues, as defined above, exceeds the limits that we have defined to the consistent offense, as the latter appears as a voluntary action that takes time and does not accept in its structure a violation of imminent attack of legal object.

This happens only to consistent attack, where the person attacked is considered as legally reacting only to those limits for which he wants to prevent a new and further violation.

For example, sustainable attack is considered the attack by the thief who has stolen a bicycle and if the owner pursues and caught the thief and the owner can take the bicycle back by the use of violence but in proportion to the attack (Battaglini, 1933, p. 340).

Attack is not considered complete even if the thief has committed the offense of theft and collides with the owner of the house in the moment he goes out the door of the house, because the owner has the right to pursuit him until he restores his right by possessing his objects. This is justified, even though the place where the owner catches the thief is very far from the place where the attack started and time has passed since the moment when the offense was committed.

Attack will be considered imminent and uncompleted (i.e. has started and continues) even when the person has reached the purpose and the right affected can be restored imminently. This happens in practice not only concerning the offence of theft but also with a category of offenses, especially with offenses relating to the freedom of the person, where the continuation of defense leads to the restoration of the previous situation, forcing the perpetrator of the complete action to formally release, for example the kidnapped person. Obviously, the defense in such case is justified if continued uninterrupted.

According to this definition, imminent attack can be understood as an attack whose infringement has started and its termination necessarily depends on defensive counterattack.

So, attack is real when it is likely to avoid definitive damage of the right that the attacker aimed to harm. So in case of theft by the use of violence, defense is allowed while the attacker is running holding the object taken by force or by the use of threat, as it is still possible to save the property (Cela, Peza, Elezi, Gjika, 1982, p. 174). In context of these cases, we conclude that the notion of imminent attack affects the meaning of counterattack. Counterattack expresses the defense that is exercised before the infringement from the attack has been realized, but not before, when it is highly probable that this violation will occur (Padovani, 1989, p. 501).

Attack should be imminent and therefore it is necessary, referring to the "time" element, to determine the moment when it starts (from where) and the moment of completion (until), for which defense can be called legitimate, considering a set of important principles. In the case of the thief who runs and throws a few meters away the items stolen from the place where the offence took place, the continuance to pursuit and apprehend him does not justify the necessary defense 
because now the attack has been completed (Fiandaca-Musco, 2002, p. 278).

Attack must not be deliberately provoked, because this condition even though it is not expressly provided for in Article 19 of the Criminal Code is included in the real attack and in its injustice from which a person is obligated to protect himself. Thus, even in the presence of an unlawful attack, the action of the person that objects a situation created and desired cannot justify the application of necessary defense required in terms of Article 19 of the Criminal Code because this situation is predicted and accepted freely by the person. When defense is done after the end of the attack we would be in front of overcoming limits of necessary defense.

Defense and attack are organically related to each other to the degree that cannot be understood without each other. Having been conditioned by the attack, when the attack ends and does not continue any more the state of necessary defense will end (Mantovani, 2002, p. 269).

Attack is considered finished (Angioni, 1994, p. 9) and does not continue when the person withdraws from further continuation of actions or has ceased aggressive actions because of counteraction, when defense has rebuffed the risk that comes from it, when it failed and cannot be repeated imminently, when it has fulfilled its mission.

So if the attacker has completed its actions and they are not a danger or threat source for the counter - attacker, any action taken by the latter cannot be justified in applying the institute of attempt for the necessary defense, and we are dealing with an action illegal and punishable. In these cases, once the attack is over and has dismissed the possibility of attack, counterattack would not be defense but revenge.

\subsection{Attack is certainly to start}

Imminent attack will certainly start when there is a substantial probability that harmful consequences would result, allowing the implementation of necessary defense although the attack has not started yet (Mantovani, 2002, p. 269).

So, we will be before an expected attack when its author has not committed any direct action yet, ultimate on the object endangered, but has committed and continues to perform preparatory actions for an attack that is expected to occur in a moment, therefore when the circumstances show that the author is trying to carry out the attack immediately. Such example is the case when the person takes the weapon and fills it or performs other preparatory actions which leave no doubt that he will attack immediately.

So attack is underway and further actions may be prevented if attack is finished by the use of a counterattack or when the attack is not consolidated because it is not fulfilled switching from a situation of danger in a situation of effective damage (Mantovani, 2002, p. 269).

Under Article 19, of the Criminal Code, imminent attack is a situation for which the probability of realizing the harmful effect is so closely that this attack can be transformed in such affect that cannot allow effective defense any more. Real attack is close to its realization and is threatening and imminent.

However, this is not a final determination regarding the definition of real attack.

Theory of law considers real attack even when it violates the judicial object by bringing consequences, but which is not finished yet, e.g. as in the case of the person who stabbed the victim with a knife and injured him and makes another move to stab him again. As it can be seen in this case, the imminent attack is the one that can bring other consequences, and any action taken contributes to make most possible and near the attack bringing other consequences.

Assessment of existence of the imminent attack is done not only through an objective assessment but also considering psychological or subjective criterion of the person.

-According to objective evaluation: This assessment refers to the specific circumstances of the case and should be objectively perceived by different forms resulting from the consequence, the means that are used and other secondary elements of the objective side, the type of object that is affected and not just the opinion or assumption of the counter attacker. So, the objective assessment refers to objective opportunities that the person has had to understand if the attack exists at the moment, in the future or has finished.

In other words, it is true that the attack is never something concrete, because it is not an accomplished fact, but it is a logical assessment of the case, a potential forecast that can be realized in the future. Assessment is based on its ability or potentiality to be realized outside, connecting it with material circumstances of the imminent and the possible affect.

-According to psychological or subjective evaluation: This evaluation is done subjectively by the person and it is important because this evaluation and the regulations of error affect in fact the existence or nonexistence of the attack. Therefore, if the person mistakenly believes that it is facing an imminent attack we are dealing with recalled or fictitious (Cela, Peza, Elezi, Gjika, 1982, p. 174) defense and rules of errors will apply here along with the element of subjective 
matter.

Therefore, the attack will certainly be analyzed in terms of an objective assessment but subjective criteria bears huge and dominant importance because ineffective attack which does not exist but it is perceived by the person at the time of defense will be assessed not objectively but subjectively.

When a person has not had any opportunity to understand that the attack is not imminent as it is finished, and he has a wrong picture on it, then it would be considered imminent.

If the person mistakenly believes that he is before an imminent attack, we are before a recalled or fictitious defense and rules of fact shall apply here subjectively.

If he has been able to understand, we will be before a finished attack and not imminent, overcrossing the limits of necessary defense.

If the person knows that the attack is over, that it is not imminent then we will face a full criminal offense committed intentionally.

Albanian criminal law recognizes objective - subjective assessment. The Supreme Court decision No. 244, dated 6.05.2009, has expressed the same standpoint, which states: "But if a person, due to the conditions created, realizes that he is before a real and unjust attack that endangers his interests and for this reason counteracts, the actions that are committed under the theory and practice of criminal law should be recognized committed for the necessary defense.

As above, the accused because of the circumstances was not able and did not have any opportunity to realize that he was not before an unlawful attack. Subjective matter of the person is important".

So, in conclusion of this decision it is found that: If a person by mistaken thinks that he is before a real and unjust attack, defense is considered lawful in cases where the person acts in error, and this should be accepted in the concrete case.

If the counter - attacker has wrongful imagination, he shall not be based solely on subjective criteria but must have an objective basis, in the sense that this mistaken visualization should be based on circumstances that have led to the need to commit the offense. Imminent attack is a necessary condition for the necessary defense and stems from the need for defense. Article 19 of the Criminal Code does not apply in those cases where the attack is future or fictional, because of the importance of the imminent attack, which consists of a concrete threat, on the way to be carried out in the moment of defense or due to a threat and fast affect. For example, it is not enough the fact that the attacker holds a weapon at the moment of reaction. It is necessary to prove that, while using the weapon or threatening to use it or acting in a way that makes it likely that he will use the weapon quickly, creates a threatening situation to the counter - attacker, necessary to be defended (Italian Court Decision No. 03494, dated 27.03.1991).

The notion of imminent attack as described above should not be confused with cases where the attack has not yet come, as may be available or clear that in the future will come. In other words, imminent attack is always real attack and different from the future attack.

In this aspect, the action carried out to avoid an attack against preparation to carry out an attack in the future cannot be described in terms of necessary defense, because the attack is not imminent and it is not known whether it can be accomplished, even if there are full details that its arrival is safe, because in the attack of this nature, the endangered person has the opportunity and sufficient time to prevent it in other ways, using legal means and appropriate ways.

Therefore, necessary defense is excluded before a future or imaginary attack because only the real attack is important.

It is rightly acknowledged that the measures taken by the injured party or by third persons to stop the attacker and hand him to competent authorities for prosecution are based on the necessary defense, from the standpoint of legal consequences, provided that limits of necessary defense are not exceeded.

Use of force to stop the attacker, or causing of damage to defense his opposition, is lawful if dictated by the need to achieve this goal. This view is accepted in legally practice but also in High Court practice of the SPRA, No. 2, dated 26.12.1963, where paragraph 8 states:

Necessary actions made by the injured person or other persons to stop the attacker and to hand him to state competent authorities, are legal actions and are equal to those committed in the state of necessary defense. In such cases the person attacked and other persons have criminal responsibility only when causing to the attacker damages that were not necessary for his detention.

The notion of imminent attack includes not only static and unchanging actions, which consist of the threat of an unlawful attack, but also cases in which the attack takes time, where the action by the attacker is not exhausted or completed in a single act. But, in these cases it cannot be fully, clearly or openly said that the action of the attacker will affect and will continue presenting consistently threatening behavior. 
Necessary defense does not apply in cases of offenses committed by negligence.

Jurisprudence of the High Court has often emphasized that circumstances must be evaluated to change the legal qualification of the offense in terms of necessary defense or accessing them, to be used as qualifying or mitigating circumstances (Albanian High Court Decision No. 134, dated 27.10.2010).

This assessment relates to the fact that if the attack has finished, it cannot be claimed the application of Article 19 of the Penal Code. If the actions of the attacker end, which means if the attacker hits only once and leaves, it means that the attack has failed and has finished and is no longer real. Under the High Court Decision No. 134, dated 27.10.2010, the attack has finished and overcoming of necessary defense limits cannot be applied, because subjectively the counter attacker knew under circumstances, that it had finished and the court has fairly convicted him for a full complete offense. Unlawful attack is considered as mitigating circumstances because the offense was committed by the victim's provocation, under Article 48 of the Criminal Code.

If by the subjective side the action by the counter - attacker would appear in the form of negligence, it could be applied the institute of overcoming the limits for the necessary defense.

Institute of necessary defense can be interwoven with that of imminent strong trauma. The latter can be considered in relation to the proportion of attack and defense, but nonetheless if conditions for necessary defense exist, mental trauma does not matter (Albanian High Court Decision No. 809, dated 15.09.2010).

\section{Standpoint between Imminent Attack and Institute of Attempt}

Article 19 on "Necessary Defense" cited above, requires inter alia that attack must be unlawful. The attack will be considered unlawful when it is against the law and hazardous.

On the other hand, Article 22 of the Criminal Code provides the notion of attempt:

"A criminal act is considered an attempt when, although the person undertakes straightforward actions to commit such criminal act, it is discontinued or is not completed due to circumstances independent of his will".

Condemning only actions due to which have started the execution of the offence and not preparatory actions. If a person would react to preparatory actions, despite the fact that they might be imminent, he would not be legitimized in front of applying the institute for the necessary defense, as they are not illegal, apart from exceptional cases when the lawmaker condemns preparation.

The concept of imminent attack coincides with the notion of attempt, as a direct action of the latter, legally objectionable, which can have consequences and affect imminently. From this, it is expressed the close relationship that exists between attempt and necessary defense.

In doctrine, there are opinions that necessary defense must be applied even in cases where preparatory actions are very close to the attempt. Let's take an example: A husband drank alcohol every day and after drinking alcohol he violated his wife and his children, thus bringing serious consequences. If we were coherent with the limit that separates preparatory actions and initiation of an attempt, we would say that the outcome of alcohol consumption would lead immediately the start of the commission of socially hazardous unlawful acts, as the exercise of violence.

And if drinking alcohol coincides with the preparatory actions and immediately after the person starts performing his direct actions under Article 22, of the Criminal Code, would the affected person be legitimized under Article 19 of the Criminal Code if he seriously wounded his wife soon after drinking alcohol? Will the preparatory action be considered not punishable and therefore not against the law?

However, we believe such actions are close to direct actions for execution and conditions that determine a behavior that is always repeated on time and in the same manner, it cannot be justified the application of Article 19 of the Criminal Code to a person that is defended from an alcoholic attacker because, under the Albanian criminal law:

1. We are dealing here with preparatory actions and these actions cannot constitute unjust attack because unjust attack should be unlawful and preparatory actions are not unlawful, they are not punishable.

2. Principle of materiality or appearance of actions outside would be affected by counteracting against an opinion that a person may have, but one person's opinion is not objectionable.

3. The principle of casual link would be violated because the action should be necessary, direct and decisive for the possibility of the arrival of the affect.

But, despite similarities between imminent attack and attempted attack, there are differences between them.

If the necessary defense for its purpose deserves a more extensive application to protect certain legal facilities determined for the attempt, this reasoning is not valid. Under Article 23 of the Criminal Code, attempt is punishable as a preliminary stage, because it is not punished a result which has not been real, but the will of the person appeared. 
In other words, if for the application of necessary defense the existence of attack can be accelerated even when it is probably expected to occur, the opposite occurs attempt because the limit where illegal behavior appears must be much closer to realization of the offense. So the distance between action and consequence attack is closest to attempt.

This means that with regard to the necessary defense, the counter - attacker can act before the action is directly addressed to him, as it is expected that it will certainly come. For example, attempt is punishable only when the action is direct, when the person takes out a pistol and points it to the defender, and the importance of attack coincided in that moment, then the counter - attacker will probably have time to shoot the gun, but will not have time to shoot a second time if the first shot fails.

In other words, chances for defense or counterattack are fewer because time is short to try and prevent the attack and having no more chances to shoot again and hit the nail of the head.

Even under the best foreign doctrine, all these findings lead to the conclusion that the imminent attack does not coincide with the full or shortcoming attempt, but with the attempt where from the total number of actions, it does not consist in an imminent attack the last action but little earlier and which coincides more closely to attempt, i.e. in that action which will be qualified as an attempt only in a slightly later moment. Therefore, the moment that immediately coincides before the start of the attempt constitutes an imminent attack.

This notion requires much more specification and deepening than this paper, as it is presented as the only possible time for the defender to prevent the attack. Beyond this attack, it could not be possible for the person attacked to prevent the attack, which can be immediately transformed in an affect for the person attacked. In Italy there is a decision of the Court Bassano d. Grappa, dated 03.03.2009, which supports this reasoning and states that: Imminent attack stems not only from consumption but also from attempts: imminent attack is a potential violation which precedes the behavior of attackers in the report with elements of objective side such as time, place and tools available to attackers and counterattacker.

Given that we referred to the institute of attempt to analyze the imminent attack, the institute of waiving plays an important role, as provided for in Article 24 of the Penal Code.

When the attacker finally waives, thus meeting the requirements provided for in Article 24 of the Criminal Code, from further actions the attack is not imminent anymore and has finished and there is no place for defense for counterattacker because unlawful attack is not imminent, real or present.

In order to provide necessary defense the attack must be real and unjust and there must be legitimate reaction. First, it must be materialized in an actual attack, which, if it is not neutralized in time, it would violate a right. Second, it has to do with the need to be defended and proportion between attack and defense.

The way the provision is expressed by the terms "necessary defense", "being forced", "the character of defense must be in proportion with the level of danger of the attack", there must be understood that the protection should be in that circumstance which may cause a greater harm to protect the legally object.

** *

Referring to the above conclusions on the notion of imminent attack in criminal - legally sense, we conclude that we are dealing with an imminent attack of an unjust infringement only in assessing the possibility of consuming a criminal offense or when it is proven the presence of a concrete figure of the offense waiting to be carried out and still unfulfilled.

Application of Article 19 in the way how it is formulated in connection with the attack requirements makes us convinced that it can be applied, and does not depend on the guilty of the attacker, as the provision does not clearly state the necessary existence of this element of the subjective side.

The fact that the provision is expressed on an unjust and not "criminal" attack means that it is sufficient for the necessary protection that the attack objectively presents social hazardous, when this hazardous is not associated with the responsibility or criminal irresponsibility of the author.

This request is in favor of protection because although as a rule an unlawful attack is criminal it happens that for objective or legal reasons its author shall not bear criminal responsibility This is the case, for example, the attack made by a person due to reckless mental state or by minors under the age of 14 years for crimes and 16 years for criminal contraventions. In these cases they do not bear criminal responsibility because there is no fault, the subjective side of the offense. Therefore, the legislator has associated the necessary defense with the objective side of the offence, due to the presence of danger posed by unlawful attack, risk that exists objectively, despite the lack of any other essential element of the offense. As a rule, motive, intent or mental attitude of the author who attacks to harmful consequences that could arise from it are indifferent to the institute of necessary defense (Muci, 2006, p. 180).

Thus we conclude that Article 19 is applied although the counter - attacker reacts to an attack without guilt and not punishable (Fiandaca-Musco, 2002, p. 281). 
In theory and practice of the criminal law, of interest has been the problem of provocation. It is duly made the question, whether the person who provoked the unlawful attack by himself or by a third person that goes to help the attacked person counterattacked is in the situation of necessary defense.

Judicial theory and practice tend in the position of rejecting the necessary defense in cases where the person attacked has provoked the attack with his unlawful behavior (Muci, 2009, p.178).

Theory and case law generally tend their position by rejecting the necessary defense in cases when the person has provoked the attack by himself by his unlawful behavior, through a deliberate provocation.

Regarding cases of deliberate provocation, to initiate an attack on oneself in order to justify the counterattack, it is clear that necessary defense cannot be legitimized, because in this situation we are in front of simulation of illegal actions. In these cases, the provocateur will be responsible for the crime committed under the provision that provides its figure.

But, it should be noted that the provocateur could be in terms of self-defense if the person provoked exceeds his defense thus creating the need for counterattack ( Italian Court Decision No. 03376, dated 12.04.1985), because provocation is unintentional to cause serious consequences.

In the case of provocation, Article 19 of the Penal Code cannot be applied to the person who provoked the attack and it cannot be applied if there are exceeded limits of necessary defense, because injustice of the attack is lacked (Italian Court Decision No.06622, dated 14.07.1984).

Application of error rules of fact in the institute for necessary defense is important. To exclude counter - attacker from criminal responsibility, i.e. to apply not only the real necessary defense but also the effective one, thus causing not to occur an imminent attack, it is necessary that every wrong imagination of the person on the existence of the imminent attack should be assessed not only by subjective side but certainly also in the elements of the objective side, from where it can be understood the subjective side.

Fictitious defense can also be apparent or unreal attack, however it should be fictional, in the sense that the wrong visualization to be defended should not be based purely on a subjective criterion side, considering only mental attitude of the author, but in concrete actions, which, although in itself is not suitable to create an imminent attack, is such to justify in the mental attitude of the authors the reasonable belief that the author is in a situation of a very fast attack (Italian Court Decision No. 16015, dated 17.11.1989).

Necessary fictitious defense contains the same elements of the necessary real defense, with the only difference that in the first case the imminent attack does not objectively exist, but it is assumed by a counterattack based on his erroneous visualization in assessing the necessary defense. If the person assesses that this error is caused by negligence, this will lead to criminal responsibility if the offense committed may exist in this form of guilt (Italian Court Decision No. 03257, dated 22.03.1991).

In conclusion, for the protection of the necessary fictitious defense there must be the same elements of the necessary real defense, with the sole exception of an imminent, unlawful and real attack, which instead of having occurred in reality it is wrongly conceived for its existence by the subject, based on a wrong evaluation but objectively reasonable (Italian Court Decision No.02564, dated 26.02.1991).

\section{Imminent Attack on a Comparative Profile}

\subsection{Article 52 of the Italian Penal Code}

Article 52 of the Italian Criminal Code provides the necessary defense institute or as otherwise called "legitimate defense" and expressly says:

"It is not punishable if a person who has committed an offense has behaved this way to protect a right for himself or of another person against the imminent risk of an unjust infringement, provided that the defense be proportionate to the offense".

From this provision, it is understood that the application of this institute is based on two important poles and similar to those of other countries dealing with attack and defense issues, with exception that this code refers to an unlawful attack and legal protection.

Unjust attack must be imminent and the future or completed attack is not accepted.

In contrast to the Albanian criminal law that uses the term attack, the Italian law refers to as risk. Imminent risk means the possibility of the arrival of a future and malicious consequence, while allowing legal protection when the attack has not yet started or the attacker has not taken action yet. This determination is widely accepted by Italian law. 
The risk must be imminent and it is not enough for it to exist. It is not enough only the possibility of the arrival of the consequence but it is required something else quid pluris, that the Italian legislator has determined in the definition of the term imminent. Solution that is needed to be given is to precisely determine the moment when the lawful defense starts and can be exercised, taking into account some important moments.

Under this law, acceleration in excess of defense does not justify this institute by diverting its goal. Space that lawful defense may occupy is for those situations for which the risk or the possibility of the arrival of the consequences is so close to its transformation into infringement, by not allowing an effective defense. Therefore, imminent risk will be considered the risk that is close to realization and is threatening.

The Italian law recognizes as imminent risk those cases when the risk is transformed into attack and that has affected or has brought consequence but which has not yet finished (Romano, 2004, p. 555; Frosali, 1958, p. 295). This author recognizes the institute of necessary defense even when actions do not cause a punishable attempt.

In this last definition, the real risk is the risk to further infringements and each prior infringement consumed make possible other future consequences. Italian Code considers imminent risk as consistent. Article 52 of the Italian Penal Code in the term that uses "imminent risk" allows the application of this institute for those actions which are not actions directly punishable as attempt, reasoning that postponing the moment of legitimate defense would make the protection of rights impossible.

According to the Italian Constitutional Court Decision, No. 46776, dated 04.12.2012, attempt is punishable even in the absence of actions that coincide with the execution of the offense or existence of an initial moment of its execution.

This court decision acknowledges the subjective theory on direct actions of the offender on the grounds that:

"Given that human action consists of two or more acts, on a logical analysis the attempt is punishable not only when it is complete and all operations are carried out, but even when the offender has committed one or more acts (not necessarily executive) which clearly and unequivocally indicate the author's willingness to commit the offense. Under this decision, and under the subjective theory as well, preparatory actions may appear in the institute of attempt when they show at the same time the author's intention to commit the offense, on the basis of a previous ex ante evaluation and due to failure to realize an independent consequence from the factors independent of its control, adaptability of causal connection in the chain of actions to reach the final consequence and the attitude to create a situation of an imminent risk and a concrete infringement.

According to this subjective theory, preparatory action can contain characteristics of an attempt when it is convenient and direct for consumption of an offense or when has the ability, on the basis of a preliminary assessment and the circumstances of the issue (place, time tools, etc.), to achieve the desired consequence and this consequence is undoubtedly near.

In contrast is the objective theory which necessarily requires that actions must be direct to the realization of the offense and action should be exclusively executable or actions that constitute the figure of an offense and in its most basic form, based on the principles of general criminal law under which preparatory actions are not punishable.

\subsection{Article 8 of the Criminal Code of Kosovo}

The Criminal Code of Kosovo has provided the notion of necessary defense in Article 8. This article states:

"Necessary defense is the defense deemed necessary to avoid illegal the, real and imminent attack to oneself or to any other person, provided that the defense be in proportion to the degree of danger posed by attack".

The notion of necessary defense has shown that in order to consider that there is necessary defense there should occur attack and defense. These elements are similar with Albanian and Italian legislation.

One of the main requirements of attack, as expressly provided by Article 8 and without making any distinction between personal goods or property, requires that attack must be imminent or real (Salihu, 2009, p. 238).

Under this recognition, attack will be considered real when it is expected to occur at any moment, from the moment it starts and until it lasts, respectively, until the end.

This means that real attack notion does not agree with the notion of the future attack, which is expected to happen in the future and neither with the attack which is finished and there is no place to be repeated imminently.

These notions are similar with the imminent attack provided for in the Albanian criminal law, saying that it does not make differences or characteristics in the theoretical plan.

With regard to the attack that is expected to start soon, the Kosovo criminal law legitimizes the institute of necessary defense even when the attacker has taken preliminary action but not it is not clarified if these actions were preparatory or not. This issue is explained by circumstances which define the purpose of the offender. If the author has 
the aim to attack, these preliminary actions will be considered punishable attempt and make the attack unlawful.

Therefore, if preparatory actions are very close or overlap with the attempt, the specific criminal act that is being committed should be taken into account.

Additionally, to make the distinction of attempt and preparation that are very close to each other the following shall be taken into account:

1. Natural link between the action taken and the action of the commission of a relevant offense figure;

2. The person's plan for committing the offense shall be considered;

3. By making an assessment to the real situation, there should be ascertained whether it is about the attack to the good defended.

By virtue of these criteria, Kosovo criminal law distinguishes between attempt and preparation. In those cases where the attack is justified, the institute of necessary defense is not justified, besides the fact error rules and fictitious or putative defense.

\section{Conclusions}

In the case of necessary defense, the attack time (action) plays a crucial role for or not exclusion from the criminal responsibility, for the fact that attack should be imminent and not later, in order to be before a necessary defense. Referring to the "time" element, attack should be imminent, in order to determine the start moment (from where) and ending moment (until when), for which protection can be regarded legitimate, given a set of important principles.

Attack is never something concrete, because it is not a realized fact but a logical assessment on the imminent, a possible prediction that can be realized in the future. Albanian criminal law recognizes objective - subjective assessment. Supreme Court decision No. 244 dated 6.05.2009 has also expressed the same view.

The concept of imminent attack coincides with the notion of attempt, as a direct action of the latter, legally punishable, which can have consequences and affects imminently. From this close determination, it is expressed the relationship that exists between attempt and necessary defense.

I am of the opinion that preparatory actions that are close to direct actions for the start of execution cannot justify the application of Article 19, of the Criminal Code, for this reason: We still have to do with preparatory actions which can not constitute unjust attack because unjust attack must be unlawful and preparatory actions are not unlawful and they are not punishable. The principle of materiality or displaying actions outside, by counteracting against a thought that a person may have, would be affected but one person's opinion is not objectionable. The principle of a causal link would be violated because action must be deemed necessary, direct and decisive for the possibility of the arrival of the effect.

After we examined the imminent attack, by taking into account legislations of some countries, we reached different conclusions. I.e., according to the Italian Constitutional Court Decision No. 46776 dated 12.04.2012, the attempt is punishable even in the absence of actions to coincide with the execution of the offense or the existence of an initial moment of its execution. Under the Criminal Code of Kosovo "If preparatory actions are very close to or overlap with the attempt, the real offence that is being committed should be taken into account".

\section{References}

Antolisei, Manuale di diritto penale, Parte generale, 2008.

Aurela Anastasi \& Luan Omari "Constitutional Law", ABC, Tirana, 2010.

Ashworth, Principles of criminal law, Oxford, 2003.

Battaglini, Sulla leggittima difesa, në Riv.ti.dir.pen., 1933.

Caraccioli, Condotta permanente e permanenza di effeti nella fattispecie criminali, in Riv.it., 1960.

Carnelutti, Teoria generale del reato, Padova, 1933.

Cela, Elezi, Peza, Gjika, Criminal Law of the Republic of Albania, General Part III, 1976.

Cela, Peza, Elezi, Gjika, Criminal Law of the People's Socialist Republic of Albania, General Part, 1982.

Crespi, Stella, Zuccala, "Commentario breve al codice penale", Ed. Cedam, Padova 1999.

De Francesco, Profili strutturali e processuali del reato permanante.

Dine, Gobert, Cases and materials on Criminal Law, 2003.

Eelezi, I., Kacupi, S., Haxhia. M., Commentary of the Criminal Code of the Republic of Albania, 2012.

Elezi, Criminal Law of the People's Socialist Republic of Albania. (Special Part), 1983

Elezi, Criminal Law, General Part, 2008.

Elezi, I., Kacupi, S., Haxhia, M., Commentary of the Criminal Code of the Republic of Albania, Geer Publications 2006,

Elezi, Kaçupi, Haxhia, Commentary of the Criminal Code of the Republic of Albania, 2011.

Elezi.I.,Criminal Law, Special Part, Erik Publications 2007.

Fiandaca Musco, Diritto penale, Parte generale, second edition, 1995.

Fiandaca.M., Musco.E. Diritto penale, Parte generale, Seconda edizione, 1997, Zanichelli Bologna. 
Fiandaca-Musco, Diritto penale. Parte generale, Bologna 2007.

Grisolia, II reato permanente, Padova 1996.

Grosso, Legittima difesa, në Diz.dir.pubbl.IV, 2006.

Hussel, Diritto e tempo.Saggi di filosofia del diritto.

Husserl G. Diritto e tempo. Saggi di filosofia del diritto, Milan 1998.

Islami, H., Hoxha, A., Panda, I., Procedura Penale, Tirana, 2007.

Ismet Elezi, Criminal Law, Special Part, 2009.

Ismet Elezi, Skënder Kaçupi, Maksim R. Haxhia, Commentary of the Criminal Code of the Republic of Albania, 2012.

Ismet Salihu, Criminal Law, General Part, 2010.

Kambovski Vllado, Criminal Law, General Part, Furkan, 2010.

Criminal Procedure Code of the Republic of Albania, 1995.

Criminal Code of the Republic of Albania, 1995.

Spanish Criminal Code, 2011.

Italian Criminal Code, 2012

French Criminal Code, 2012.

German Criminal Code, 2011.

Kosovo Criminal Code, 2011.

Commentary of the Criminal Code of the Republic of Albania, Ismet Elezi, Skënder Kaçupi,

Commentary of the Criminal Code, Special Part (draft), State University of Tirana, 1960.

Constitution of the Republic of Albania.

L'efficacia nel tempo della legge penale,1969.

Leone, II tempo nel diritto penale sostantivo e processuale, Naples.

Levi, Tempus commissi delicti, Annali, 1993.

Levi, Tempus commissi delicti, Annali, 1993.

Lotito G. Note minime in ordine alla competenza per territorio nel nuovo codice di procedura penale nei casi di reato continuato, Arch. Proc. Pen., 1990.

Lotito G., Note minime in ordine alla competenza per territorio nel nuovo codice di procedura penale nei casi di reato cpntinuato, Arch.Proc.Pen., 1990.

Mantovani, Diritto penale, parte speciale, 2001.

Mantovani, Diritto penale, Parte generale, 2009.

Marinuci.G., Dolcini.E., Manuale di diritto penale, Parte Generale, Terza edizione, Giuffre.

Muci, Sh., Criminal Law , General Part, Ora Publications, 2006.

Munoz Conde, Garcia Aran, Derecho penal, parte general, Valencia, 2004.

Padovani, Difesa legittima, në Dig.disc.pen.,III, Torino, 1989.

Pagliaro A., Legge penale nel tempo, in Enc. dir., XXVIII, Milan, 1973.

Pagliaro, Principi di diritto penale. Parte generale, Milano, 1998.

Pecorella C., Legge intermedia: aspetti problematici e prospettive de lege ferenda, në

Peverati, Osservazioni sulla legittima difesa,Turin, 1942.

Pulitano V., Legalità discontinua? Paradigmi e problemi di diritto intertemporale, in

Puto, A., Public international law, Tirana, 2008.

Rampioni, Contributo alla teoria del reato permanente, Padova 1988.

Regina, Unita`e pluralita`di azioni a proposito del reato continuato.,in Riv.it.1968.

Riv. it. dir. proc. pen., 2002,

Riz.R., Lineamenti di diritto penale, Parte generale, Seconda edizione 2000, Cedam.

Romano-Grasso,Commentario sistematico del codice penale, 2004.

Ronco, M, Ardizzone, S., Codice penale ipertestuale, Commentario anca dati di giurisprudenza, Seconda edizione, Utet giuridica 2007.

Salihi, I., Criminal Law, General Part, Pristina.

Shefqet Muci, Criminal Law, General Part, 2006.

Skender Kacupi, Phases of the criminal offence commission, Dissertation, 1990.

Taushani, Papuli, nova, Commentary of the Criminal Code of the People's Socialist Republic of Albania, first volume, publication of the Ministry of Justice, 1964.

Vinciguerra S., Diritto penale inglese comparato - Principi, Padova, 2002.

Vinciguerra S.-Dassano F., Scritti in memoria di Giuliano Marini, Naples-Rome, 2010.

Vllado Kambovski, Criminal Law, General Part, 2010.

\section{Websites}

Supreme Court

http://www.gjykataelarte.gov.al/

Constitutional Court

http://www.gjk.gov.al/

General Prosecutor's Office

http://www.pp.gov.al/

http://www. dirittoweb.org

ECHR

http://www.coe.int 